\title{
Management of dual traumatic arterial- venous fistula from a single shotgun injury: a case report and literature review
}

\author{
Rakan Nasser Eldine, Hassan Dehaini, Jamal J Hoballah and Fady Fayez Haddad*i(
}

\begin{abstract}
Background: Traumatic arteriovenous fistula (TAVF) is an uncommon vascular entity that arises in various locations, often from penetrating injuries, with a wide spectrum of signs and symptoms. This case report highlights the importance of suspecting multiple TAVFs after a single gunshot wound, especially if it involves pellets. It also sheds light on adapting treatment, whether endovascular or open repair, to the location and characteristics of each fistula.

Case presentation: A 35-year-old male, with history of shotgun wound 5 months earlier, presented to our clinic with right lower extremity (RLE) edema and pain. Arterial duplex scan and subsequent angiogram showed two TAVFs at the popliteal and posterior tibial (PT) arteries, both of which could not be exactly localized with a computed tomography angiography (CTA) due to artifacts. The fistula connecting the posterior tibial artery (PTA) and vein was repaired endovascularly using a covered-stent, while the fistula between the popliteal artery and vein was repaired surgically. Postoperative follow-up at 3 months showed no arteriovenous fistula (AVF), patent vessels and distal stent stenosis at the PTA.
\end{abstract}

Conclusions: Patients who sustain gunshot injuries with shrapnel or pellets and develop TAVF consequentially need to be followed up with the possibility of multiple AVFs in mind. Arterial duplex scan is highly sensitive to detect those AVFs, yet angiography remains gold standard, particularly with extensive metal artefacts. Endovascular repair, when feasible, should be considered first, unless the patient is unstable or has anatomical constraints that increase the risk of complications. Lastly, surgeons should be weary of deep venous thrombosis (DVT), the Branham effect and arterial aneurysmal dilation postoperatively.

Keywords: Traumatic, Arteriovenous fistula, Posterior tibial artery, Popliteal artery, Case report

\section{Background}

An arteriovenous fistula (AVF) is an aberrant pathway between an artery and a vein. It can either be congenital or acquired [1]. Acquired AVFs are mostly iatrogenic, but they can be traumatic as well. Traumatic AVFs (TAVFs) constitute up to $3.9 \%$ of vascular injuries [2] and have been mentioned in a multitude of case reports and series. However, TAVF remains a challenging

\section{* Correspondence: fh16@aub.edu.lb}

Division of Vascular \& Endovascular Surgery, Department of Surgery, American University of Beirut Medical Center, PO Box 11-0236, Riad el Solh, Beirut 1107 2020, Lebanon pathology due to the absence of official guidelines in the midst of variable presentations, multiple locations and different treatment modalities. In this paper, we report an interesting case of a 35-year-old male who acquired two TAVFs of the lower extremity, one of which was treated via an endovascular approach, while the other required an open surgery. This case report is written in accordance with the CARE guidelines [3].

\section{Case presentation}

A 35-year-old male, previously healthy, presented to our clinic with swelling of his right thigh associated with

(c) The Author(s). 2020 Open Access This article is licensed under a Creative Commons Attribution 4.0 International License, which permits use, sharing, adaptation, distribution and reproduction in any medium or format, as long as you give appropriate credit to the original author(s) and the source, provide a link to the Creative Commons licence, and indicate if changes were made. The images or other third party material in this article are included in the article's Creative Commons licence, unless indicated otherwise in a credit line to the material. If material is not included in the article's Creative Commons licence and your intended use is not permitted by statutory regulation or exceeds the permitted use, you will need to obtain permission directly from the copyright holder. To view a copy of this licence, visit http://creativecommons.org/licenses/by/4.0/ The Creative Commons Public Domain Dedication waiver (http://creativecommons.org/publicdomain/zero/1.0/) applies to the data made available in this article, unless otherwise stated in a credit line to the data. 
pain of 4 weeks duration. The patient's history was pertinent for a shotgun injury to his right lower extremity (RLE) 5 months prior to presentation, which had involved numerous pellet injuries to his popliteal artery, posterior tibial artery (PTA), and tibioperoneal (TP) trunk. His injuries had required multiple direct arterial and venous repairs, in addition to four compartments fasciotomies that were closed with skin grafts. Additionally, he had developed posttraumatic neuropathic pain and mild RLE weakness, which were improving and being followed up by neurology. During the interval time, patient was doing well until 4 weeks prior to this presentation.

Upon physical examination, patient had a marked swelling of his proximal RLE and a bruit on auscultation distally. He had an absent posterior tibial (PT) pulse, normal dorsalis pedis (DP) pulse and decreased range of motion (ROM) at the ankle. There were no signs of limb ischemia nor venous hypertension.

Arterial duplex scan showed high diastolic flow in the PTA and an arterialized flow in the posterior tibial vein (PTV). A reversed flow in the distal PTA was also noted. Indeed, a communication was eventually found at the level of mid-to-distal leg between PTA and PTV (Fig. 1). Computed tomographic angiography (CTA) showed early filling of the right popliteal and superficial femoral veins (SFVs), as well as dilated superficial veins of RLE, but could not identify the location of the AVF due to multiple pellets artifacts (Fig. 2). However, the brisk and substantial filling of the femoral vein on the arterial phase raised the possibility of a more proximal fistula than the distal leg. Angiography was planned with intension to treat depending on findings.

The right common femoral artery (CFA) was accessed and arteriography was done to confirm the previously diagnosed AVF between PTA and PTV. However, there was an additional distal popliteal AVF at the level of the tibial tuberosity. The decision was to offer surgical repair for the popliteal AVF; however, for the PTA one, an endovascular option would be done because of the extensive scarring from the initial exploration, in addition to the split-thickness skin graft at the fasciotomy sites.
The endovascular procedure was as follows:

- A 6-French (Fr) sheath (Cook, Indiana, USA) was placed in the distal popliteal artery followed by a guidewire over a 4-Fr vertebral catheter in the PTA proximal to the AVF. The fistula was localized with severe stenosis just beyond it (Fig. 3).

- A $3 \times 15 \mathrm{~mm}$ Euphora balloon (Medtronic, Ca, USA) was used for pre-dilatation, followed by placement of a $3 \times 18 \mathrm{~mm}$ Bentley stent (InnoMed, Germany) in the PTA at the level of the AVF (Fig. 4).

- Post-procedure arteriogram showed total exclusion of the AVF with a patent artery distally and a sluggish but antegrade flow that reaches the plantar arch (Fig. 5). Foot and leg were briskly perfused through patent anterior tibial and peroneal arteries.

The patient was discharged on dual antiplatelet therapy (DAPT): aspirin $100 \mathrm{mg}$ and clopidogrel $75 \mathrm{mg}$. On follow-up, the patient had persistent swelling of his RLE. Duplex scan showed resolution of the distal AVF, normal venous flow in the PTV, reduced flow in the proximal PTA and strong retrograde filling of the distal PTA, which was likely due to distal stent stenosis. Moreover, the AVF between the popliteal artery and vein was well visualized this time. A month later, the patient was admitted for surgical repair of his popliteal AVF.

The surgical procedure was done through a posterior approach and a lazy $\mathrm{S}$ incision was performed. The short saphenous vein and sciatic nerve branches were protected. The popliteal artery and vein, which was dilated and had a thrill, were dissected and then controlled proximally and distally with vessel loops. The communication site was identified (Fig. $6 \mathrm{~A}$ ) and both vessels were debrided and primarily repaired (Fig. 6 B). Distal pulses were palpable on completion with no thrill in the vein. The patient was discharged 2 days later on clopidogrel $75 \mathrm{mg}$ and rivaroxaban $20 \mathrm{mg}$ for 3 months.

At 3 months follow-up, the swelling and pain had resolved. His duplex showed no AVFs, yet it revealed an occluded right PTA at the distal stent with good reversed flow distally.

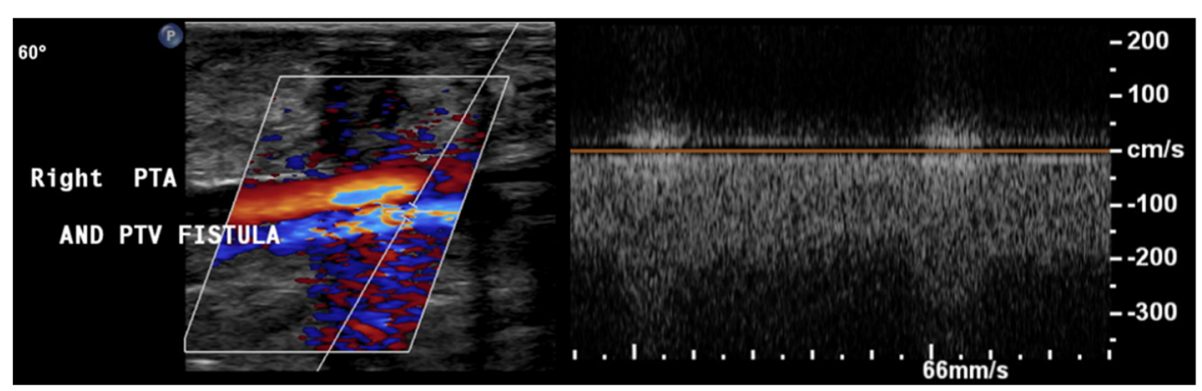

Fig. 1 Arterial duplex scan showing an AVF between right PTA and PTV 


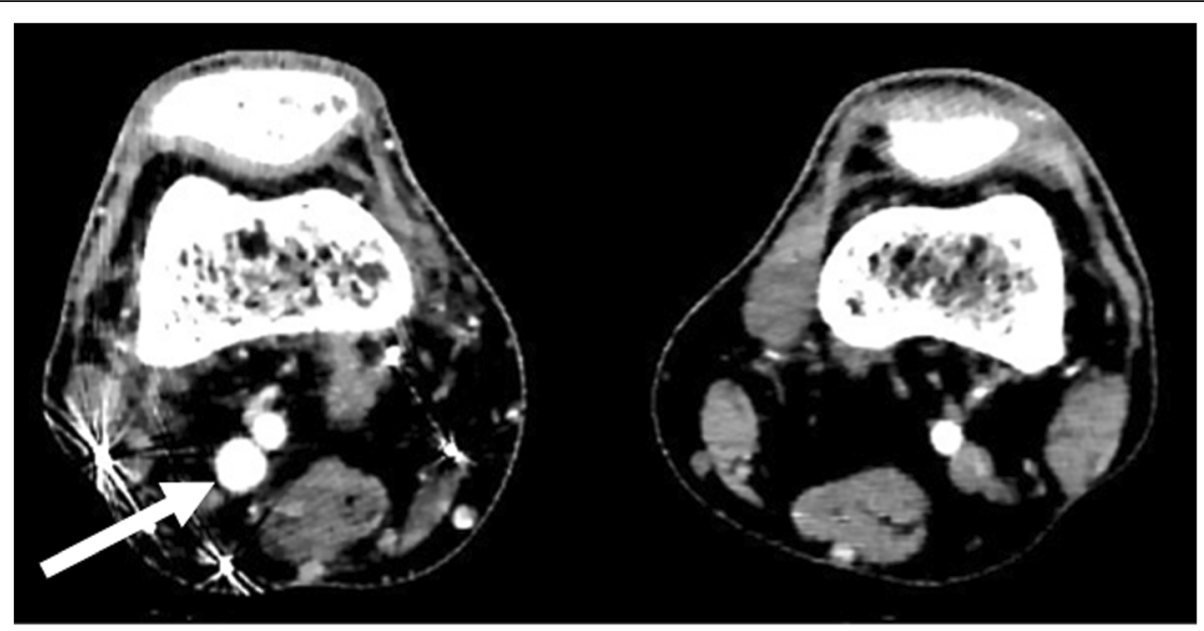

Fig. 2 CTA showing early filling of right popliteal vein, indicating the presence of an AVF. Pellet artifacts in the posterior-lateral distal thigh

\section{Discussion and conclusions}

TAVF is caused by penetrating trauma, blunt trauma and fractures [4-6]. In our area, which is a conflict zone, the most common etiology in our experience is shrapnel injury. TAVFs are classified into central and peripheral, the latter being more common, and among peripheral TAVFs, the lower extremity is the most frequent site [6]. Our patient developed PT and popliteal AVFs, which represent 8.6 and $1.4 \%$ respectively of traumatic fistulas [6]. TAVF manifests in three broad categories: localized early symptoms like those of our patient, such as swelling and pain [5]; local complications like arterial and venous insufficiencies [5, 7-10]; systemic complications like high-output heart failure and pulmonary hypertension $[11,12]$.

Table 1 summarizes the case reports and series available in the literature about TAVF. It demonstrates the wide variability of TAVF in terms of site, time to diagnosis, clinical manifestation and treatment modalities, explaining the lack of formal guidelines for diagnosing and treating TAVF.

Current practice considers arterial duplex scan as the initial screening method for a suspected arterial injury. It has been shown to have a sensitivity of $95 \%$ and a specificity of 98 to $99 \%$ in detecting arterial injuries [23, 24], one of which is TAVF. In our case, duplex scan detected initially one of our patient's two AVFs. It is likely that the second one was overlooked once the fistula flow was attributed to the tibial, more distal one detected first. The popliteal fistula was readily detected on subsequent follow up, particularly following the first procedure.

There are no clear guidelines as to what the next diagnostic step is. Although angiography remains the gold standard, it is common among practitioners to do a

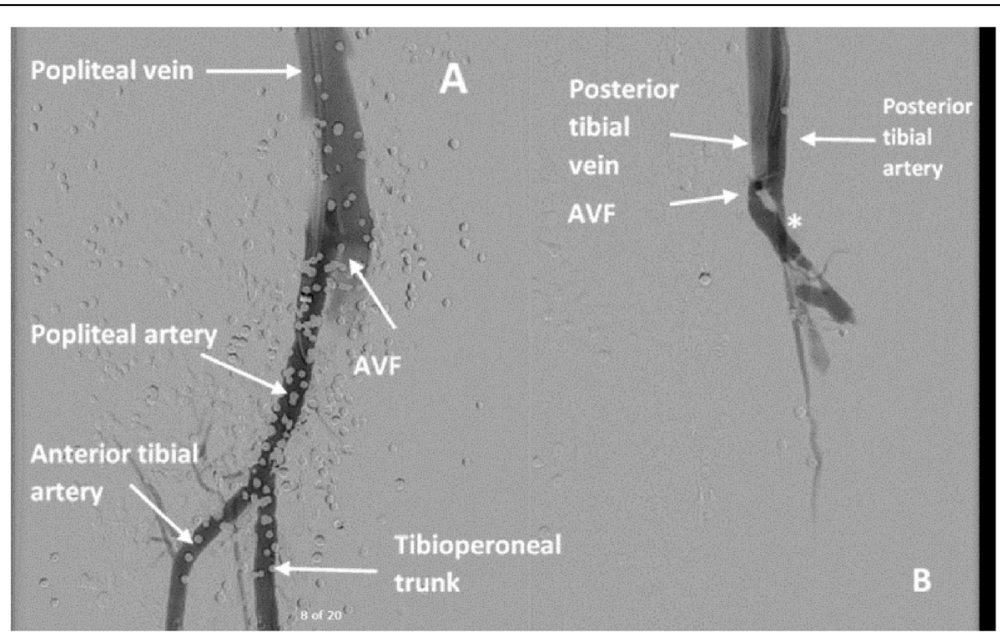

Fig. 3 a Angiogram showing an AVF between popliteal artery and vein. b Angiogram showing an AVF between PT artery and vein. Post-AVF stenosis isdemarcated with an * 


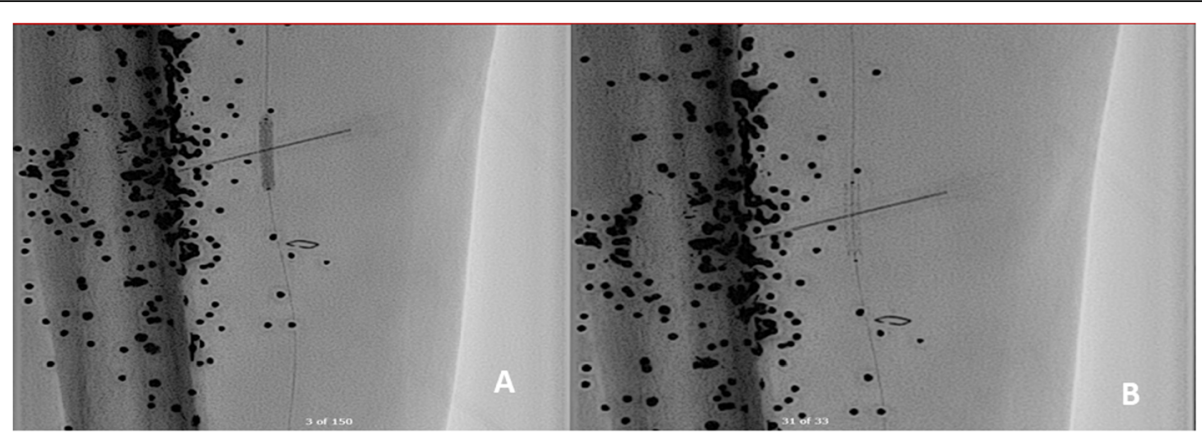

Fig. 4 a A $3 \times 15 \mathrm{~mm}$ coronary balloon used for pre-dilatation in PTA. b A $3 \times 18 \mathrm{~mm}$ covered stent in the PTA at the level of AVF

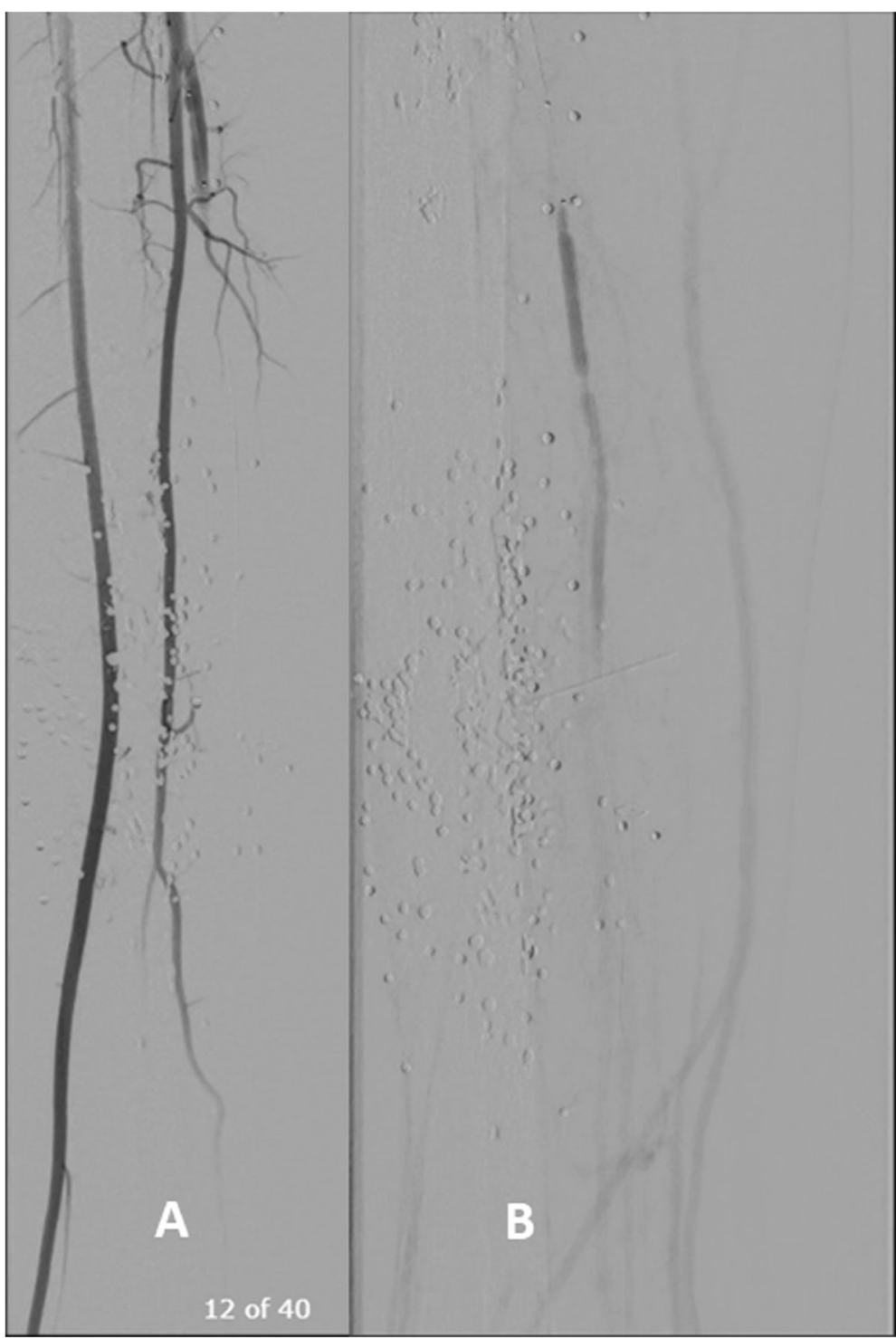

Fig. 5 a Absence of AVF between PTA and PTV post stenting. b Sluggish flow but patent PTA 
A

B

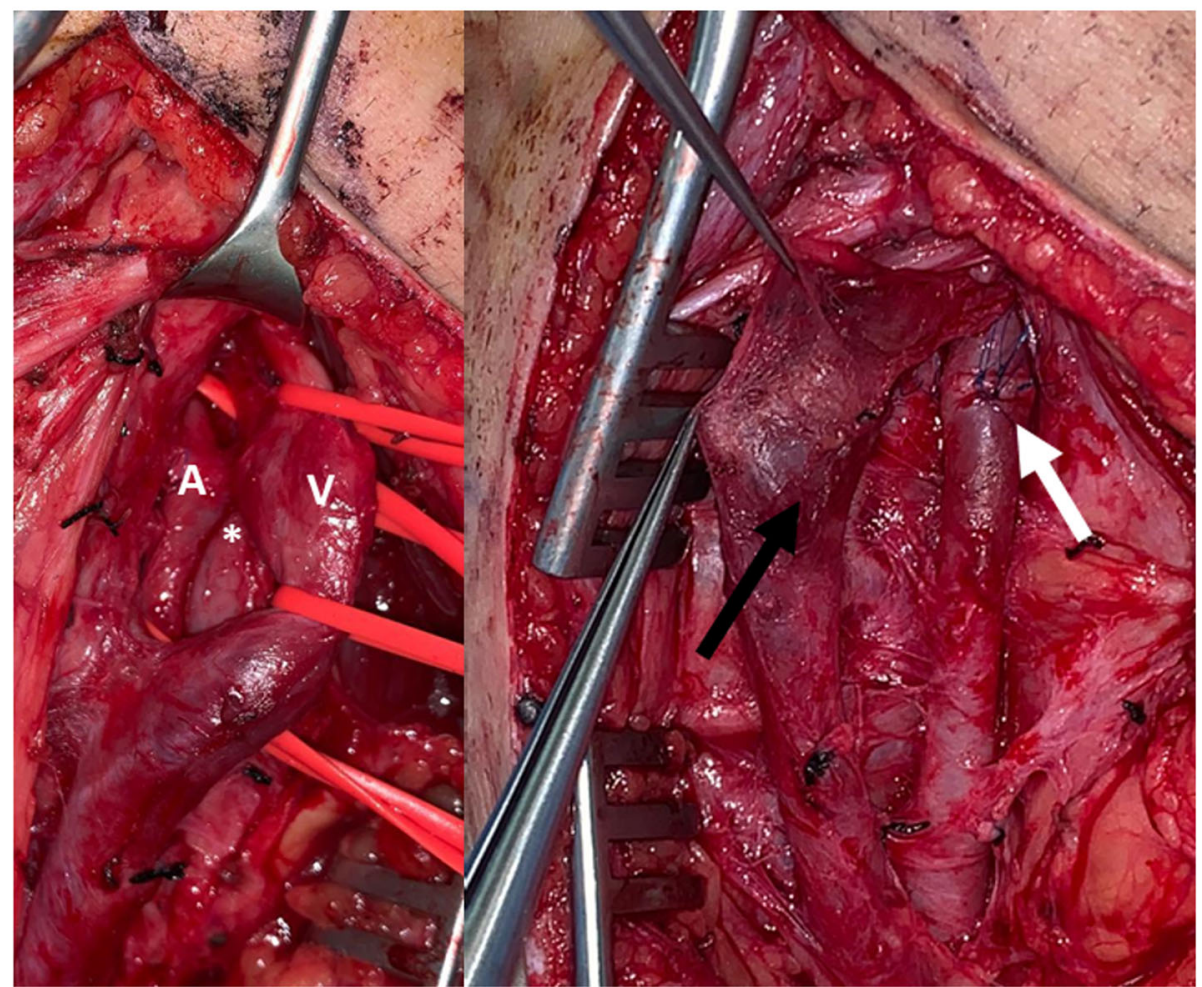

Fig. 6 a Surgical exploration of the AVF $\left(^{*}\right)$ between popliteal artery $(A)$ and vein $(V)$, both of which have been controlled proximally and distally. b Popliteal artery and vein post debridement and AVF repair. (White arrow is arterial sutures and black arrow is venous sutures)

CTA as a second step (Table 1) [16, 25]. In a systematic review and meta-analysis by Jens et al., CTA was shown to have a sensitivity and specificity of 96.2 and $99.2 \%$ respectively [26]. The lack of significant difference between the sensitivities of duplex scan and CTA decreases the utility of CTA as a second diagnostic measure after duplex scan. This is further inferred by the increased risk of artifacts in CTA due to shrapnel in the setting of a TAVF, as in the case of our patient, whose both AVFs could not be directly and accurately visualized. We have had similar experience with other blast injuries that include multiple metal shrapnel, readily detected on plain $\mathrm{x}$-rays, and multiple pellets from shotguns shot at close range (thus clustered in distribution). Hence, we recommend liberal use of angiography following duplex scan rather than CTA, if the latter is not needed for other bodily injuries. This is in line as well with one of the largest series reporting on 27 operated cases of TAVF, the majority (except the ones who were unstable) had eventually angiography as a localizing modality [21].

The introduction of endovascular techniques has revolutionized vascular surgery and trauma. Unless there are restrictions like hemodynamic instability [22], patients with TAVF deserve a chance to be treated with endovascular procedures, which carry less postoperative risks and minimize magnitude of the procedure and length of stay [27]. Availability of such treatments should not compromise durability, especially in younger individuals; patient selection remains of essence. Options include AVF embolization using coils, detachable balloons or embolization glue, such as NBCA-lipiodol [9, 11, 17], and placement of stent grafts to exclude AVFs (Table 1) $[5,16,18]$. Despite the established safety of endovascular repair, patients remain at risk of detachment, embolization and stent misplacement [7, 9], as well as endoleak [16]. In a nice index case by Sahin et al. [11], surgically repairing a misplaced stent in the femoral vein across the fistula, illustrating what originally could have been a simple repair, is transformed into a complex reconstruction, especially on a young individual with low surgical risk to start with. Moreover, embolizing the feeding artery rather than the AVF if unsuccessful can prohibit or complicate further endovascular attempts [19], or force an operation.

In our case, we placed a stent-graft to treat the PT AVF without facing any complications. Nevertheless, in the presence of two other vessels run-off and good retrograde filling of the PTA, complete embolization of the artery would have been an option. Indeed, with the latest follow up and the occlusion at stent level, our 
Table 1 Summary of case reports and series discussed

\begin{tabular}{|c|c|c|c|c|c|c|}
\hline Author & $\begin{array}{l}\text { Mechanism } \\
\text { of Injury }\end{array}$ & Location (artery) & $\begin{array}{l}\text { Time to } \\
\text { Diagnosis }\end{array}$ & Clinical Presentation & $\begin{array}{l}\text { Diagnostic } \\
\text { Method }\end{array}$ & Treatment \\
\hline $\begin{array}{l}\text { Ariyoshi } \\
\text { et al. [13] }\end{array}$ & Shrapnel & SFA & 2 weeks & Pseudoaneurysm & Angiography & Open surgery \\
\hline $\begin{array}{l}\text { Frishman } \\
\text { et al. [14] }\end{array}$ & GSW & SFA & 63 years & Arterial aneurysm, Heart failure & Angiography & Open surgery \\
\hline Kim et al. [5] & Blunt injury & SFA & 3 months & $\begin{array}{l}\text { Iliac vein thrombosis, Venous } \\
\text { hypertension, Pseudoaneurysm }\end{array}$ & CTA & Stent graft \\
\hline $\begin{array}{l}\text { Morano } \\
\text { et al. [15] }\end{array}$ & GSW & Popliteal & 1 month & Pseudoaneurysm & Angiography & Open surgery \\
\hline $\begin{array}{l}\text { Gorsi et al. } \\
{[16]}\end{array}$ & GSW & SFA & 8 years & & CTA, Doppler US & Stent graft \\
\hline $\begin{array}{l}\text { Sahin et al. } \\
\text { [7] }\end{array}$ & Stab wound & SFA & 1 year & $\begin{array}{l}\text { Claudication, Stent } \\
\text { graft misplacement }\end{array}$ & $\begin{array}{l}\text { Angiography, } \\
\text { Doppler US }\end{array}$ & Open surgery \\
\hline $\begin{array}{l}\text { Roth et al. } \\
\text { [8] }\end{array}$ & Open fracture & PTA & 1 year & $\begin{array}{l}\text { Non-healing ulcer, } \\
\text { Impaired wound healing }\end{array}$ & Angiography & Open surgery \\
\hline $\begin{array}{l}\text { Donmez } \\
\text { et al. [9] }\end{array}$ & GSW & PTA & 10 years & $\begin{array}{l}\text { Heart failure, Venous } \\
\text { ulcers, Varicose veins }\end{array}$ & $\begin{array}{l}\text { Angiography, } \\
\text { Doppler US }\end{array}$ & Detachable balloon, NBCA \\
\hline $\begin{array}{l}\text { Vagefi et al. } \\
{[11]}\end{array}$ & GSW & Internal iliac & 40 years & Atrial fibrillation, Heart failure & CTA & Embolization, Stent graft \\
\hline $\begin{array}{l}\text { Veldhoen } \\
\text { et al. [12] }\end{array}$ & GSW & Profunda femoral & 6.5 years & Pulmonary hypertension & $\begin{array}{l}\text { Angiography, } \\
\text { Doppler US }\end{array}$ & Open surgery \\
\hline $\begin{array}{l}\text { Topuz et al. } \\
{[17]}\end{array}$ & Stab wound & Profunda femoral & & & Doppler US & Coil embolization \\
\hline $\begin{array}{l}\text { Spirito et al. } \\
\text { [18] }\end{array}$ & Blunt injury & ATA & 2 months & & Doppler US & Stent graft \\
\hline $\begin{array}{l}\text { Yilmaz et al. } \\
\text { [19] }\end{array}$ & & Internal iliac & 6 years & Venous outflow obstruction & & $\begin{array}{l}\text { Stent graft by transvenous } \\
\text { approach after failed open } \\
\text { surgery }\end{array}$ \\
\hline $\begin{array}{l}\text { Orrapin et al. } \\
\text { [20] }\end{array}$ & $\begin{array}{l}\text { (A) Stab } \\
\text { wound } \\
\text { (B) Shotgun } \\
\text { wound }\end{array}$ & $\begin{array}{l}\text { (A) SFA } \\
\text { (B) External iliac, } \\
\text { CFA, SFA }\end{array}$ & $\begin{array}{l}\text { (A) } 18 \text { years } \\
\text { (B) } 2 \text { years }\end{array}$ & $\begin{array}{l}\text { (A) Venous aneurysm causing } \\
\text { DVT postop } \\
\text { (B) CHF preop, Branham effect } \\
\text { postop }\end{array}$ & $\begin{array}{l}\text { (A) Angiography, } \\
\text { Doppler US } \\
\text { (B) CTA }\end{array}$ & $\begin{array}{l}\text { (A) Open surgery } \\
\text { (B) Open surgery }\end{array}$ \\
\hline $\begin{array}{l}\text { Franz et al. } \\
{[21]}\end{array}$ & Stab wound & Popliteal & 3 months & Stent thrombosis & CTA & Stent graft \\
\hline $\begin{array}{l}\text { Sahin et al. } \\
\text { [22] }\end{array}$ & $\begin{array}{l}23 \times \text { GSWs, } \\
4 x \text { penetrating } \\
\text { injuries }\end{array}$ & $\begin{array}{l}26 \times \cup E \\
1 \times L E\end{array}$ & $\begin{array}{l}\text { Mean } 16 \pm 8 \\
\text { months }\end{array}$ & & Doppler US & $\begin{array}{l}2 x \text { ligation \& } 1^{\circ} \text { repair of artery } \\
\text { and vein, } 5 x \text { arterial graft } \\
\text { interposition plus } 1^{\circ} \text { vein repair, } \\
20 x \text { arterial and venous graft } \\
\text { interposition repair }\end{array}$ \\
\hline
\end{tabular}

ATA anterior tibial artery; CFA common femoral artery; CHF congestive heart failure CTA Computed tomography angiography; DVT deep venous thrombosis; GSW Gunshot wound; LE lower extremity; PTA posterior tibial artery; SFA superficial femoral artery; UE upper extremity; US ultrasonography

intervention has eventually acted like an embolization procedure. It is worth noting that the early stent failure we encountered is likely due to stent sizing, which is the result of the varying PTA diameter across the fistula. Prior to angioplasty, PTA just beyond the fistula had severe stenosis, which caused our stent to be undersized, a common etiology for stent restenosis [28]. Moreover, a large number of indications in the reported surgical series were actually unsuccessful attempts at or failure of an endovascular treatment [21], speaking only of the challenging nature of those procedures and the high level of expertise to achieve technical success. Our proposed algorithm for management of pellets/shrapnels induced TAVF is summarized in Fig. 7. Concerning the sequence in dual fistulas, while some suggest repairing the larger fistulas first and leaving the smaller ones to reduce venous thrombosis [20], our situation was different since we caught the AVF rather early after the events; no venous aneurysms were present and only moderate venous dilatation. In any case, we elected to keep anticoagulation following the repair of the second, more proximal fistula for 3 months.

While cases of repairing popliteal AVFs endovascularly have been reported, we elected to surgically repair this one due to the potential increased risk of stent fracture and thrombosis across the knee joint, especially in a 


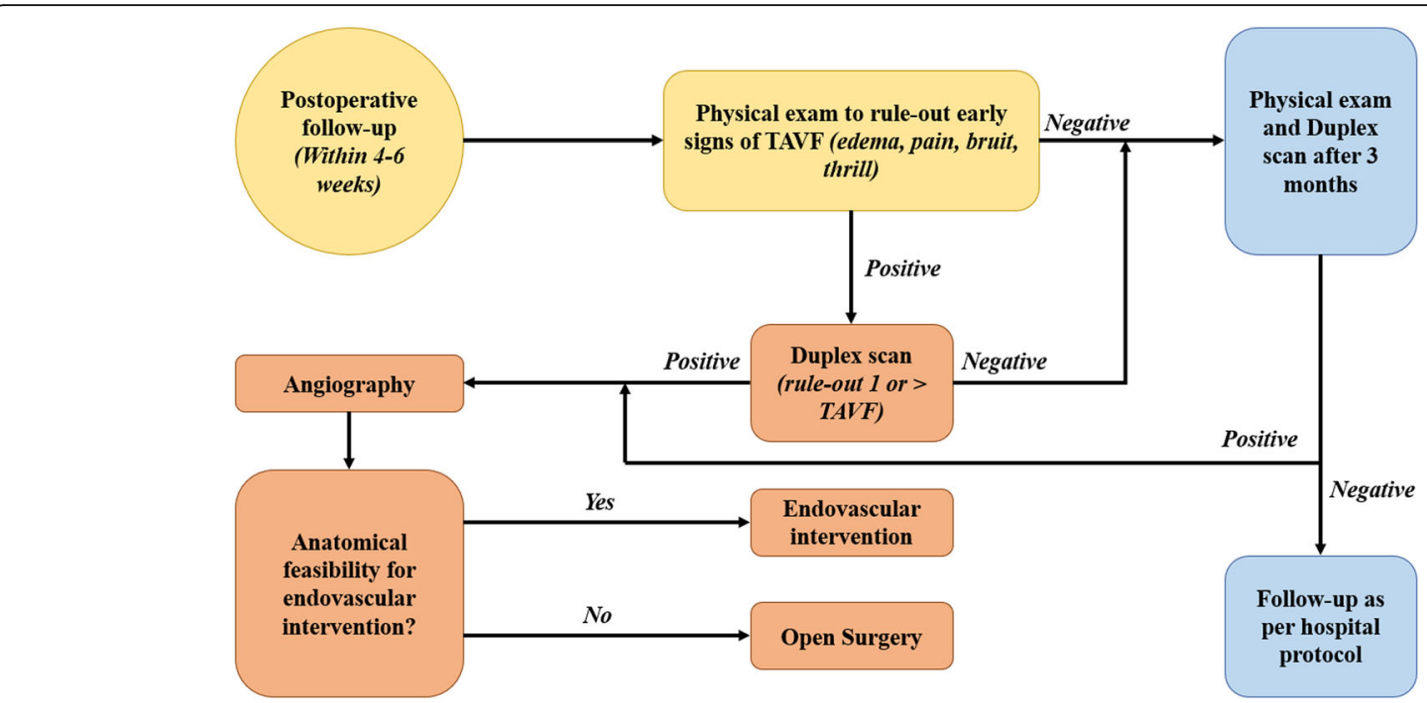

Fig. 7 Proposed treatment algorithm for TAVF caused by pellet or shrapnel injury

young active individual $[28,29]$. This was the scenario in the popliteal case reported by Franz and Jump [28], especially that a stiffer stent was used originally for the repair. For us, the surgical posterior approach was the obvious choice considering the location behind the knee joint, the very focal nature and the scarring medially from the previous exploration and tissue loss.

Correction of AVFs cause rapid resolution of symptoms, including the systemic ones $[11,12,29,30]$. There are three postoperative complications, however, that warrant special consideration; chronic TAVFs can cause venous dilatation and aneurysms, which in the setting of decreased blood velocity post repair, can precipitate the formation of venous thromboembolism (VTE) [20]. Therefore, close monitoring and DVT prophylaxis are necessary. We elected to keep our patient on anticoagulation for 3 months following the repair. The second complication is the Branham effect, which is reflex bradycardia immediately after repairing an AVF due to the sudden increase in systemic vascular resistance [20]. In case of surgical correction, Orrapin et al. recommend clamping the fistula prior to definitive excision to check for possible hemodynamic instability [20]. The third complication is aneurysmal arterial dilation proximal to AVF even post closure. Although brachial artery aneurysm is what has been reported [31, 32], the possibility of it occurring in different arteries is plausible [33]. Vigilant follow-up for new mass or swelling at site of AVF with the aid of duplex scan is the best option for early detection and treatment.

In conclusion, although TAVF is an established complication and what we are presenting is only a case report, it is an interesting illustration of this pathology that highlights the importance of vigilant follow up in pellet injuries and explores dual management options: endovascular and open repair. We recommend following up patients who sustain injuries with shrapnel or pellets with the possibility of more than one AVF in mind. Duplex scan is highly sensitive to detect those AVFs, though more than one could be present as in this case. Angiography should remain gold standard, particularly with extensive metal artefacts. Endovascular repair when feasible should be considered first, unless the patient is unstable or has anatomical constraints that increase the risk of complications (Fig. 7). Lastly, surgeons should be weary of DVT, the Branham effect and arterial aneurysmal dilation postoperatively.

\section{Abbreviations}

AVF: Arteriovenous fistula; CFA: Common femoral artery; CTA: Computed tomographic angiography; DAPT: Dual antiplatelet therapy; DP: Dorsalis pedis; DVT: Deep venous thrombosis; Fr: French; PT: Posterior tibial; PTA: Posterior tibial artery; PTV: Posterior tibial vein; RLE: Right lower extremity; ROM: Range of motion; SFV: Superficial femoral vein;

TAVF: Traumatic arteriovenous fistula; TP: Tibioperoneal; VTE: Venous thromboembolism

\section{Acknowledgements \\ Not Applicable.}

\section{Authors' contributions}

$\mathrm{RN}, \mathrm{FH}$ and JH performed the operations. RN and HD drafted the manuscript under the supervision and review of both $\mathrm{FH}$ and $\mathrm{JH}$. All authors have read and approved the manuscript.

\section{Funding}

This research did not receive a grant from any funding agency.

\section{Availability of data and materials}

All data supporting the conclusions of this study are included in this published article.

Ethics approval and consent to participate

The need for ethics approval was waived by our institutional review board. 


\section{Consent for publication}

A written informed consent was obtained from the patient to publish this case report.

\section{Competing interests}

The authors declare that they have no competing interests.

Received: 2 March 2020 Accepted: 27 July 2020

Published online: 05 August 2020

\section{References}

1. Regina G, Impedovo G, Angiletta D, Marotta V, Lillo A, Pestrichella F, et al. A new strategy for treatment of a congenital Arteriovenous fistula of the neck. Case report. Eur J Vasc Endovasc Surg. 2006;32(1):107-9.

2. GP, H LH. Haimovici's vascular surgery, principle and technique. Cambridge: Mass: Blackwell Science; 1996.

3. Riley DS, Barber MS, Kienle GS, Aronson JK, von Schoen-Angerer T, Tugwell $P$, et al. CARE guidelines for case reports: explanation and elaboration document. J Clin Epidemiol. 2017;89:218-35.

4. Freischlag JA, Sise M, Quinones-Baldrich WJ, Hye RJ, Sedwitz MM. Vascular complications associated with orthopedic procedures. Surg Gynecol Obstet. 1989;169(2):147-52.

5. Kim DS, Kim SW, Lee HS, Byun KH, Choe MS. Distal femoral Arteriovenous fistula with iliac vein thrombosis after blunt trauma. Vascular Specialist Int. 2017;33(1):37-9.

6. Kollmeyer KR, Hunt JL, Ellman BA, Fry WJ. Acute and chronic traumatic arteriovenous fistulae in civilians. Epidemiology and treatment. Arch Surg (Chicago, III : 1960). 1981;116(5):697-702.

7. Sahin S, Cinar B, Bilgin SN, Celik L, Eren EE. Surgical repair of a posttraumatic arteriovenous fistula complicated by stent-graft misplacement. Cardiovasc Intervent Radiol. 2005;28(1):87-9.

8. Roth P, Heiss C, Koshty A, Niemann B, Boening A. Posttraumatic arteriovenous fistula of the distal posterior tibial artery as cause of delayed wound healing in an unrecognized arterial injury. Thoracic Cardiovasc Surgeon Rep. 2014;3(1):67-70.

9. Donmez H, Mavili E, Toker B, Ozturk MH, Soylu SO, Hekimoglu B. Use of a balloon and N-butyl-2-cyanoacrylate for treatment of arteriovenous fistula. Cardiovasc Intervent Radiol. 2008;31(Suppl 2):S111-4.

10. Rezvani M. Traumatic arteriovenous fistula after kickboxing injury: a case report and review of the literature. Arch Trauma Res. 2014;3(1):e15575.

11. Vagefi PA, Kwolek CJ, Wicky S, Watkins MT. Congestive heart failure from traumatic arteriovenous fistula. J Am Coll Surg. 2009;209(1):150.

12. Veldhoen RA, Chan W, Mahaffey R, D'Arsigny CL. Traumatic Pulmonary Hypertension Secondary to Arteriovenous Fistula and Remote Gunshot Wound. Can J Cardiol. 2019;35(2):229 e11-.e13.

13. Ariyoshi H, Miyaso S, Aono Y, Kawasaki T, Sakon M, Monden M. Delayed presentation of superficial femoral artery injury: report of a case. Surg Today. 2001:31(5):471-3.

14. Frishman W, Epstein AM, Kulick S, Killip T. Heart failure 63 years after traumatic arteriovenous fistula. Am J Cardiol. 1974;34(6):733-6.

15. Morano JU, Burkhalter JL, CR Daniel Jr. Bilateral Popliteal Arteriovenous Fistulas J Trauma 1987;27(5):577-578.

16. Gorsi U, Agarwal V, Savlania A, Behra A, Sandhu MS. Endovascular Management of Lower Limb Arteriovenous Fistula Presenting 8 years after gunshot injury. Vasc Endovasc Surg. 2019;1538574419870679.

17. Topuz M, Cosgun M, Sen O, Cayli M. Coil embolization of a traumatic arteriovenous fistula of the lower extremity. Turk Kardiyoloji Dernegi arsivi Turk Kardiyoloji Derneginin yayin organidir. 2015;43(8):724-6.

18. Spirito R, Trabattoni P, Pompilio G, Zoli S, Agrifoglio M, Biglioli P. Endovascular treatment of a post-traumatic tibial pseudoaneurysm and arteriovenous fistula: case report and review of the literature. J Vasc Surg. 2007:45(5):1076-9.

19. Yilmaz S, Erdogan A, Luleci E. Transvenous embolization and stent placement for an internal iliac arteriovenous fistula with central iliac vein occlusion. J Vasc Int Radiol. 2004;15(4):399-404

20. Orrapin S, Arworn S, Rerkasem K. Acute deep vein thrombosis in venous aneurysm following closure of the chronic traumatic Arteriovenous fistulae of the lower extremities. Case Rep Surg. 2016;2016:1375214.

21. Franz RW, Jump MA. Endovascular repair of post-traumatic, concomitant popliteal artery pseudoaneurysm and arteriovenous fistula. Int J Angiology. 2009;18(1):41-4.
22. Sahin M, Yucel C, Kanber EM, llal Mert FT, Bicakhan B. Management of traumatic arteriovenous fistulas: A tertiary academic center experience. Ulusal travma ve acil cerrahi dergisi. 2018;24(3):234-8.

23. Bynoe RP, Miles WS, Bell RM, Greenwold DR, Sessions G, Haynes JL, et al. Noninvasive diagnosis of vascular trauma by duplex ultrasonography. J Vasc Surg. 1991;14(3):346-52.

24. Pezeshki Rad M, Mohammadifard M, Ravari H, Farrokh D, Ansaripour E, Saremi E. Comparing color Doppler ultrasonography and angiography to assess traumatic arterial injuries of the extremities. Iran J Radiol. 2015;12(1):e14258.

25. Ilonzo N, Goss S, Yang C, Dudkiewicz M. A case of superficial femoral Arteriovenous fistula and severe venous stasis ulceration, Managed with an Iliac Extender Prosthesis. Case Rep Vasc Med. 2017;2017:9460958.

26. Jens S, Kerstens MK, Legemate DA, Reekers JA, Bipat S, Koelemay MJW. Diagnostic performance of computed tomography angiography in peripheral arterial injury due to trauma: a systematic review and metaanalysis. Eur J Vasc Endovasc Surg. 2013;46(3):329-37.

27. Selby JB Jr. Interventional radiology of trauma. Radiol Clin N Am. 1992;30(2): 427-39.

28. Pal N, Din J, O'Kane P. Contemporary Management of Stent Failure: Part One. Interventional Cardiology (London, England). 2019;14(1):10-6.

29. Shindo S, Honda Y, Katsu M, Kaga S, Inoue H, Matsumoto M. Recovery of cardiomegaly after treatment of traumatic popliteal arteriovenous fistula. Circ J. 2009;73(4):776-8.

30. Imai D, Mii S, Tanaka K, Matsumoto T, Maehara Y. High-output heart failure due to post-traumatic peroneal arteriovenous fistula. J Vasc Surg. 2014;59(4):1121-2.

31. Ferrara D, Di Filippo M, Spalla F, Giribono AM, Viviani E, Santagata A, et al. Giant true brachial artery aneurysm after hemodialysis fistula closure in a renal transplant patient. Case Rep Nephrol Dial. 2016;6(3):128-32.

32. Toyota S, Inoue K, Kurose S, Yoshino S, Nakayama K, Yamashita S, et al. True brachial artery aneurysm after arteriovenous fistula closure following renal transplantation: a case report and literature review. Surgical Case Rep. 2019:5(1):188.

33. Basile C, Antonelli M, Libutti P, Teutonico A, Casucci F, Lomonte C. Is there a link between the late occurrence of a brachial artery aneurysm and the ligation of an arteriovenous fistula? Semin Dial. 2011;24(3):341-2.

\section{Publisher's Note}

Springer Nature remains neutral with regard to jurisdictional claims in published maps and institutional affiliations.

Ready to submit your research? Choose BMC and benefit from:

- fast, convenient online submission

- thorough peer review by experienced researchers in your field

- rapid publication on acceptance

- support for research data, including large and complex data types

- gold Open Access which fosters wider collaboration and increased citations

- maximum visibility for your research: over $100 \mathrm{M}$ website views per year

At $\mathrm{BMC}$, research is always in progress.

Learn more biomedcentral.com/submissions 